\title{
Posterior Subcapsular Cataract Grade 2
}

National Cancer Institute

\section{Source}

National Cancer Institute. Posterior Subcapsular Cataract Grade 2. NCI Thesaurus. Code C135202.

A stage of posterior subcapsular cataract characterized by $30 \%$ of the posterior capsule obscured by opacity. (Modified LOCS II) 